\title{
Integração de Fungicidas à Refrigeração no Controle de Podridão Pós-Colheita em Frutos de Meloeiro
}

\author{
Daniel Terao $^{1}$, Sônia M.A. de Oliveira ${ }^{2}$, F. Marto P. Viana ${ }^{1}$, Adroaldo G. Rossetti ${ }^{1}$ \\ \& Carmem C. M. de Souza ${ }^{3}$
}

${ }^{1}$ Embrapa Agroindústria Tropical, Cx. Postal 3761, CEP 60511-110, Fortaleza, CE, e-mail: daniel@cnpat.embrapa.br; ${ }^{2}$ UFRPE/DEPA/Fitossanidade, CEP 52171-900, Recife, PE; ${ }^{3}$ Estagiária do Curso de Agronomia da UFC

(Aceito para publicação em 20/10/2005)

Autor para correspondência: Daniel Terao

TERAO, D., OLIVEIRA, S.M.A., VIANA, F.M.P., ROSSETTI, A.G. \& SOUZA, C.C.M. Integração de fungicidas à refrigeração no controle de podridão em frutos de meloeiro. Fitopatologia Brasileira 31:089-093. 2006.

\begin{abstract}
RESUMO
As podridões pós-colheita constituem fator de risco nas exportações. No entanto, o número de produtos registrados para o tratamento pós-colheita de frutos de melão (Cucumis melo) é reduzido. Objetivou-se neste trabalho avaliar a influência dos fungicidas thiabendazole, azoxystrobin e imazalil a 30, 10 e 400g i.a/100 l, no desenvolvimento de Fusarium pallidoroseum e estudar o efeito deles, combinados à refrigeração, no controle de podridão em melão. Thiabendazole e imazalil inibiram 100\% do crescimento micelial e esporulação de F. pallidoroseum, enquanto o azoxystrobin 87,09\% da esporulação. A refrigeração inibiu o desenvolvimento de lesões sobre os frutos tratados com os fungicidas e inoculados com $10^{7}$ conídios/ml de F. pallidoroseum. No armazenamento à temperatura ambiente, até o $6^{\circ}$ dia de armazenamento, os fungicidas mostraram-se efetivos, sendo que o azoxystrobin e thiabendazole controlaram, eficientemente, a severidade e tamanho de lesão até 12 e 16 dias de armazenamento, respectivamente. Sob refrigeração o melhor controle foi obtido em frutos tratados com thiabendazole e imazalil. Quando retirados da refrigeração, frutos tratados com fungicidas mantiveram os mesmos níveis de controle da doença até o $20^{\circ}$ dia. Quanto à severidade, azoxystrobin e imazalil diferiram da testemunha, e para o tamanho da lesão apenas o azoxystrobin. No armazenamento refrigerado contínuo, o índice de doença mantevese baixo até o final da avaliação (34 dias). Os fungicidas foram eficientes no controle da incidência e tamanho de lesão, destacando-se o thiabendazole e imazalil no controle da severidade, enquanto que no desenvolvimento de lesão espontânea no pedúnculo do fruto, o imazalil.
\end{abstract}

Palavras-chave adicionais: melão, Fusarium pallidoroseum, controle químico.

\begin{abstract}
Integration of fungicides and refrigeration for the control of melon rot

Postharvest decay caused by quiescent fungi represents a risk for fresh fruit export. Nevertheless, the number of melon (Cucumis melo) products registered for postharvest treatment is still very low. The objective of this work was to evaluate the influence of three fungicides (thiabendazole, azoxystrobin and imazalil at 30, 10 and $400 \mathrm{~g}$ a.i/100 l) on mycelium growth and sporulation of Fusarium pallidoroseum and to compare the effect of these fungicides combined with low temperatures for the control of postharvest fungal pathogens on melons. Thiabendazole and imazalil inhibited $100 \%$ of fungal mycelial growth and sporulation while azoxystrobin inhibit $87.09 \%$. Refrigeration inhibited lesion development in melon treated with fungicides and inoculated with $10^{7} \mathrm{conidia} / \mathrm{ml}$ suspension. All tested fungicides were effective to control the incidence of post-harvested fungal pathogens at room temperature for up to six days of storage. Thiabendazole and azoxystrobin were efficient in reducing severity and lesion size for up to 12 and 16 days of storage, respectively. Under refrigeration, better control was obtained with thiabendazole and imazalil. When withdrawn from a refrigerated environment, the fungicides were able to maintein control until day 20. For severity, azoxystrobin and imazalil differed from the control; for lesion size, only azoxystrobin differed. During 34 days in refrigerated storage, the fungicides controlled equally for incidence and lesion size while for severity, a better control was obtain with thiabendazole and imazalil. Imazalil had the best control of spontaneous lesions that occurred on fruit peciolous.
\end{abstract}

Additional keywords: melon, Fusarium pallidoroseum, chemical control.

Com o intuito de elevar os padrões de qualidade e competitividade da fruticultura brasileira ao patamar de excelência requerido pelo mercado internacional, em bases voltadas para o sistema integrado de produção, sustentabilidade do processo e expansão da produção, emprego e renda, o Ministério de Agricultura e Abastecimento implantou o Programa de Produção Integrada de Frutas
(PIF). Dentre as 14 espécies frutícolas contempladas pelo PIF está o melão (Cucumis melo L.), em função de sua expressiva contribuição na balança comercial de frutas frescas (Andrigueto \& Kososki, 2003). Na pauta das exportações de 2002, o melão foi a segunda fruta fresca de maior peso econômico (US\$ 37,8 milhões), sendo superado apenas pela manga (Mangifera indica L.) (US\$ 50,8 
milhões) (COEX, 2003, Comunicação Pessoal).

Apesar desta rápida expansão, alguns segmentos da cadeia produtiva do melão nacional são ainda bastante frágeis, e pouco estudados, como é o caso da patologia póscolheita. Os patógenos em pós-colheita, principalmente os quiescentes, causam grandes transtornos aos atacadistas, varejistas e principalmente aos importadores de frutas, uma vez que os sintomas das doenças irão aparecer durante o armazenamento e transporte, em frutos aparentemente sadios, podendo causar grandes perdas (Sommer, 1982).

Inúmeros patógenos têm sido associados às podridões de frutos de melão (Snowdon, 1990; Huang et al., 2000). Uma podridão pós-colheita tem sido observada comumente ocorrendo em plantios de meloeiro no Estado do Rio Grande do Norte. A infecção ocorre ainda no campo (pré-colheita) e a penetração do patógeno se dá na região do corte do pedúnculo. Mesmo após a transferência para as câmaras frias, o patógeno continua a sua patogênese, podendo destruir totalmente o fruto ou causar lesões que afetam sua comercialização (Colares, 2000). O patógeno associado ao apodrecimento do fruto do meloeiro foi identificado como sendo o Fusarium pallidoroseum (Cooke) Sacc. (Gadelha, 2002).

Dentre os inúmeros preceitos que compõem a PIF, está a segurança alimentar, estabelecendo regras rígidas que levam em consideração os resíduos de agroquímicos, permitindo o monitoramento e a rastreabilidade do produto, por meio do número identificador estampado no selo da caixa. As frutas poderão ser, então, identificadas desde a fonte de produção até o seu destino final (Andrigueto \& Kososki, 2003), reforçando assim a importância do Receituário Agronômico, bem como a restrição "monitorada" da utilização nos tratamentos fitossanitários, apenas, de produtos registrados para cada cultura, tanto no país de origem como no país importador. Existem atualmente poucos produtos disponíveis no mercado nacional registrados para o tratamento de frutos de melão.

Tem-se observado que a utilização de apenas uma forma de controle isoladamente, na maioria das vezes, não possibilita um controle eficaz de doenças, recomendandose, portanto, o manejo integrado combinando diferentes mecanismos de controle, destacando-se na pós-colheita a regulação, através do controle das condições do ambiente de armazenamento. Segundo Sommer (1982), o manejo da temperatura é um fator tão crítico no controle de doenças pós-colheita, que os demais métodos são denominados, em alguns casos, de suplementares à refrigeração.

Assim sendo, no presente trabalho se estudou a eficiência de três fungicidas (thiabendazole, imazalil e azoxystrobin) em três condições de armazenamento (temperatura ambiente, ambiente refrigerado durante 15 dias, seguido do armazenamento no ambiente e refrigeração contínua durante todo o período de armazenamento) no controle de podridão em pós-colheita de frutos de melão.

Os experimentos foram conduzidos no Laboratório de Fitopatologia da Embrapa Agroindústria Tropical, em
Fortaleza, CE, em duas etapas. A primeira consistiu na avaliação da eficiência dos fungicidas no controle do $F$. pallidoroseum em laboratório e a segunda no controle do fungo em frutos de melão cv. Orange Flesh.

Na avaliação do in vitro do efeito de fungicidas no desenvolvimento de F. pallidoroseum, discos de cultura do fungo, crescido em meio batata-dextrose-ágar (BDA) com sete dias de idade, foram transferidos para o centro de placas de Petri com meio BDA contendo os fungicidas thiabendazole, azoxystrobin e imazalil, com suas respectivas dosagens de 30, 10 e 400g i.a/100 l. Como testemunha utilizou-se apenas o meio BDA, sem a adição de fungicidas. Em seguida as placas foram mantidas em temperatura ambiente $\left(25 \pm 2{ }^{\circ} \mathrm{C}\right) \mathrm{com}$ fotoperíodo de $12 \mathrm{~h}$. O delineamento estatístico utilizado foi inteiramente casualizado com dez repetições. Avaliou-se, diariamente, o crescimento micelial durante sete dias, com o auxílio de uma régua milimetrada, medindo-se o diâmetro da colônia em dois sentidos diametralmente opostos. Aos sete dias de incubação, avaliou-se a esporulação adicionandose $20 \mathrm{ml}$ de água destilada esterilizada sobre a superfície da colônia, removendo-se o crescimento fúngico com o auxílio de uma escova de cerdas macias. A suspensão obtida foi filtrada através de gaze de camada dupla esterilizada e a contagem de conídios realizada, utilizando-se o hemacitômetro tipo Neubauer.

No estudo da eficiência de fungicidas no controle de F. pallidoroseum em frutos de melão, utilizaram-se frutos de melão cv. Orange Flesh, provenientes da região produtora em Mossoró - RN, colhidos no período quente e seco (outubro a novembro), lavados com água e sabão, desinfestados com Álcool 70\% e de acordo com cada tratamento imersos em solução fungicida de thiabendazole, azoxystrobin e imazalil, nas dosagens de 30, 10 e 400g i.a/ 100 l, respectivamente, durante 1 min. Em seguida, esses frutos foram inoculados com uma suspensão de $10^{7}$ conídios/ $\mathrm{ml}$ de F. pallidoroseum em quatro pontos eqüidistantes na superfície do fruto, previamente ferido e acondicionados em caixas de papelão (quatro frutos por caixa), que foram mantidas durante 36 h em câmara úmida. Depois de retiradas da câmara úmida, as caixas foram separadas aleatoriamente em três lotes, sendo cada lote composto de 12 caixas correspondendo aos quatro tratamentos (testemunha, thiabendazole, azoxystrobin e imazalil) com três repetições por tratamento. Os frutos foram armazenados em três condições ambientais: o primeiro lote em temperatura ambiente $\left(29 \pm 1{ }^{\circ} \mathrm{C}\right.$ e umidade relativa de $65 \pm 2 \%$ ), o segundo em câmara fria $\left(10 \pm 2^{\circ} \mathrm{C}\right.$ e umidade relativa $90 \pm$ $3 \%)$ por 15 dias sendo em seguida armazenado em temperatura ambiente (simulando o período de permanência em porões refrigerados em transporte marítimos entre Brasil e Europa, e o período de vida de prateleira durante a distribuição), e o terceiro em câmara fria durante todo o período de armazenamento, que foi de 34 dias. Os frutos testemunha do mesmo lote, foram apenas lavados e inoculados.

O ensaio foi conduzido em delineamento inteiramente casualizado em arranjo fatorial $(4 \times 3)$, sendo a unidade 
Integração de fungicidas à refrigeração no controle da podridão...

experimental correspondente a uma caixa com quatro frutos, totalizando 12 frutos por repetição. Foram avaliadas as seguintes variáveis: incidência, severidade, tamanho de lesão, a cada dois dias, durante 34 dias após a inoculação. As avaliações de severidade da doença foram feitas utilizando-se escala de notas de 0 a 5 , em que $0=$ ausência de lesão; $1=$ soma de lesões até $10 \mathrm{~mm}$; 2= soma de lesões de 11 a $20 \mathrm{~mm}$; 3= soma de lesões de 21 a $40 \mathrm{~mm}$; 4= soma de lesões de 41 a $60 \mathrm{~mm}$; e $5=$ soma de lesões maiores que 60 mm. A avaliação da incidência foi feita pela contagem do número de lesões em cada fruto.

Ao longo das avaliações surgiram lesões espontâneas, em dois diferentes locais não inoculados: no pedúnculo, causada por $F$. pallidoroseum e na superfície do fruto, por Alternaria sp., que também foram avaliadas através da mesma escala de severidade de 0 a 5 .

A análise de variância (ANOVA) foi realizada pelo programa estatístico (GLM Procedures, SAS Institute, Cary, NC) e as médias dos resultados comparadas pelo teste de Tukey $(\mathrm{P}=0,05)$.

Observaram-se diferenças altamente significativas entre os efeitos dos tratamentos utilizados, tanto no crescimento micelial como na esporulação do fungo. Os isolados de $F$. pallidoroseum apresentaram maior sensibilidade a thiabendazole e imazalil, que propiciaram uma inibição de $100 \%$ no crescimento micelial e esporulação, enquanto o azoxystrobin, apesar de reduzir apenas 23\% do crescimento micelial, inibiu 87,09\% da esporulação em relação à testemunha.

Os resultados obtidos sobre a eficiência de fungicidas no controle de F. pallidoroseum em frutos mostraram diferenças significativas para todas as variáveis avaliadas, assim como para as interações entre elas.

A refrigeração, de maneira generalizada, contribuiu para diminuir o desenvolvimento de lesões, causadas por $F$. pallidoroseum em frutos de melão inoculados, inibindo $81,6 \%$ da incidência, $86,4 \%$ da severidade, $96,1 \%$ do tamanho de lesões e $86,5 \%$ de lesões provenientes de infecções espontâneas causadas pelo fungo, que surgiram no pedúnculo do fruto. A refrigeração também influenciou no número de lesões espontâneas de Alternaria sp, reduzindo a severidade das mesmas em 96,2\%. Apesar de apresentar efeito sobre o desenvolvimento de F. pallidoroseum, a baixa temperatura não foi letal ao fungo, que apenas manteve-se quiescente, retomando seu desenvolvimento normal ao ser retirado da refrigeração.

Os fungicidas foram efetivos no controle do patógeno, observando-se interações significativas entre eles e os diferentes ambientes de armazenamento. De modo geral, no armazenamento em ambiente as podridões se desenvolveram rapidamente devido a ocorrência de temperaturas elevadas, ao redor de $30{ }^{\circ} \mathrm{C}$, condição bastante favorável ao crescimento do fungo, refletindo as precárias condições de armazenamento no mercado interno do melão, onde a refrigeração é ainda uma realidade bastante remota. Nessas condições, até o $6^{\circ}$ dia de armazenamento, os fungicidas mostraram-se igualmente efetivos no tocante ao controle da incidência da doença, diferindo estatisticamente da testemunha. Azoxystrobin e thiabendazole controlaram, eficientemente, a severidade e tamanho da lesão até os 12 e 15 dias de armazenamento, respectivamente.

Nas condições de armazenamento refrigerado descontínuo (15 dias sob refrigeração e 19 dias sob temperatura ambiente), observa-se que durante o armazenamento refrigerado ocorreu uma expressiva diminuição na taxa de desenvolvimento da doença quando comparado a frutos testemunha armazenados em temperatura ambiente (Figura 1). Os frutos tratados com fungicidas apresentaram uma paralisação no incremento da incidência (Figura 1A) e severidade (Figura 1B) da doença e na evolução de infecções espontâneas no pedúnculo (Figura 1D), durante o período de armazenamento refrigerado. $\mathrm{O}$ azoxystrobin inibiu o crescimento da lesão até o final da avaliação, aos 34 dias de armazenamento (Figura 1C). De maneira geral, os incrementos na doença, medidos através das variáveis avaliadas, foram sempre inferiores nos frutos tratados com os fungicidas quando comparados com os frutos do tratamento testemunha. Ao serem retirados da refrigeração, os frutos tratados com os fungicidas mantiveram os mesmos níveis de doença até o $20^{\circ}$ dia (cinco dias de armazenamento em temperatura ambiente), iniciando a partir de então uma evolução crescente dos sintomas até o $34^{\circ}$ dia (Figura 1).

Apesar das avaliações terem se prolongado até o $34^{\circ}$ dia, considerando-se 15 dias de armazenamento a $10{ }^{\circ} \mathrm{C}$, simulando o período médio do frete marítimo frigorificado até a Europa e quatro dias adicionais em temperatura ambiente, que segundo Aharoni et al. (1997), corresponderia o tempo de venda em varejo de melão, verificou-se aos 20 dias (Tabela 1) de armazenamento, que em relação ao controle da incidência e severidade de infecção no pedúnculo, os fungicidas foram igualmente eficientes. Com relação à severidade de lesões inoculadas, os tratamentos com azoxystrobin e imazalil diferiram da testemunha, enquanto que para o tamanho da lesão apenas o azoxystrobin diferiu estatisticamente da testemunha.

Vale ressaltar que a temperatura registrada no armazenamento ambiente de $29 \pm 1^{\circ} \mathrm{C}$ é mais elevada que a que ocorre normalmente nos locais de venda na Europa que se situa ao redor de $20{ }^{\circ} \mathrm{C}$ (Aharoni et al., 1997). Isso pode ter concorrido para um processo de deterioração mais acelerado dos frutos a partir do $20^{\circ}$ dia. Provavelmente, se a temperatura de armazenamento ambiente fosse mais adequada, a sanidade dos frutos se prolongaria por um período maior.

No armazenamento refrigerado contínuo, o índice de doença, manteve-se relativamente baixo, até o final da avaliação, aos 34 dias. Os fungicidas testados foram igualmente eficientes no controle da incidência e tamanho de lesão. Com relação à severidade da doença o thiabendazole e imazalil foram numericamente superiores, apesar de não terem diferido estatisticamente do azoxystrobim, enquanto que para a lesão espontânea no 

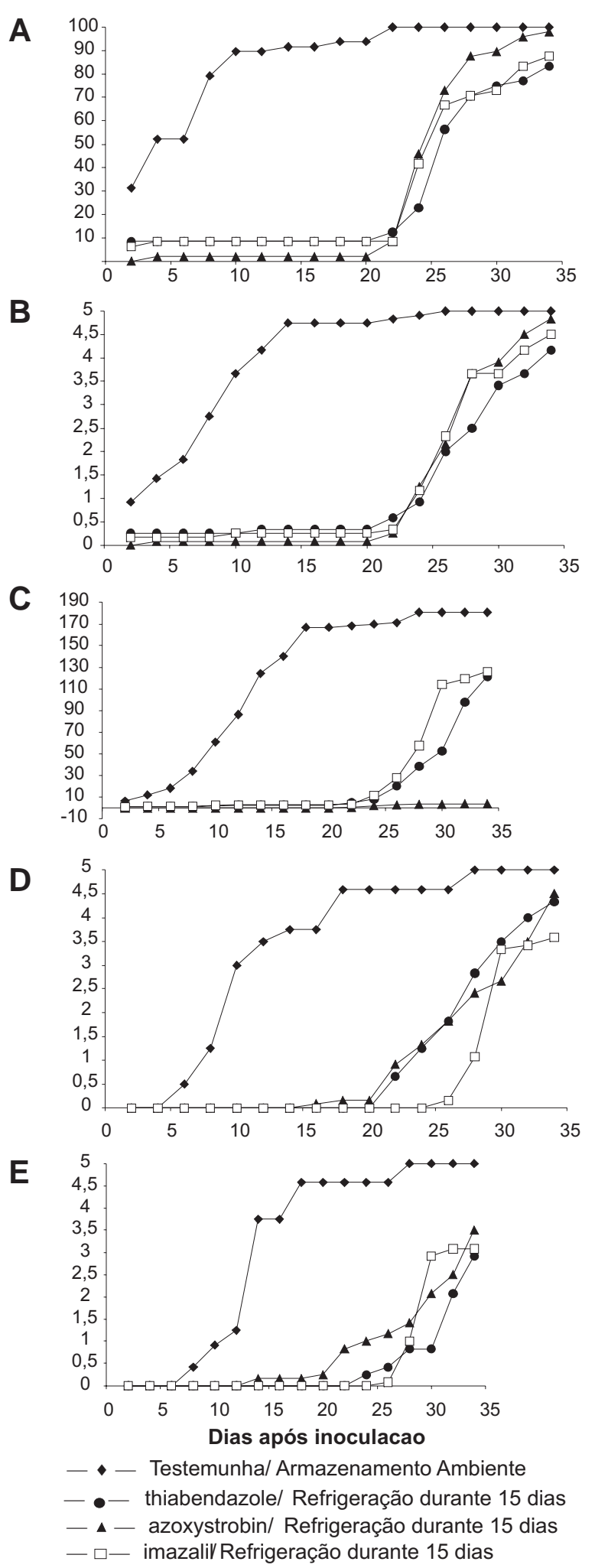

FIG. 1 - Efeito de fungicidas no controle de podridões póscolheita em frutos de meloeiro (Cucumis melo) cv. Orange Flesh, armazenados 15 dias sob refrigeração $\left(10 \pm 1^{\circ} \mathrm{C}\right.$ e $90 \pm 3 \%$ UR) e 19 dias sob temperatura ambiente. Incidência (A), severidade (B) e tamanho da lesão (C) de Fusarium pallidoroseum nos locais de inoculação. Severidade de lesões espontâneas de $F$. pallidoroseum (D) e de Alternaria sp. (E) pedúnculo do fruto o imazalil foi o melhor tratamento. Para a severidade da podridão de Alternaria, apesar do imazalil apresentar a menor média, os tratamentos com os três fungicidas não diferiram estatisticamente da testemunha (Figura 2).

O thiabendazole é um fungicida sistêmico que atua sobre sítios específicos, inibindo a polimerização da tubulina e mitose, assim mutações em genes correspondentes possibilitariam o surgimento de raças resistentes. O imazalil é um inibidor da biossíntese de ergosterol (Nakaune et al., 1998), enquanto o azoxystrobin é um princípio ativo do grupo das estrobirulinas, desenvolvido a partir de compostos naturais produzidos por cogumelos, que atua na inibição da respiração mitocondrial de fungos, impedindo a transferência de elétrons entre o citocromo b e o citocromo c (Barlett et al., 2002).

Atualmente, apenas o thiabendazole apresenta registro para o tratamento pós-colheita de frutos de melão no Brasil. Apesar da eficiência deste fungicida demonstrada neste trabalho, é fundamental a inclusão de outros princípios ativos no programa de controle, uma vez que o uso continuado de um mesmo princípio ativo possibilita a seleção de estirpes resistentes de patógenos (Rosenberg \& Meyer, 1981; Prusky et al., 1985). Segundo Spotts \& Cervantes (1986), é comum o surgimento de raças de fungos resistentes a fungicidas do grupo dos Benzimidazóis, como thiabendazole, de maneira que nessas condições, as podridões são mais severas quando fungicidas desta classe são utilizados no tratamento de frutos (Sugar \& Powers, 1986).

Em virtude da diversidade de modos de ação de cada produto, é recomendável o uso combinado desses diferentes fungicidas no tratamento de frutos, no sentido de evitar o desenvolvimento de patógenos com sensibilidade reduzida aos mesmos.

Concluindo-se, então, que a integração da refrigeração ao controle químico proporcionou significativa redução no desenvolvimento de podridão pós-colheita em frutos de melão. No entanto, os produtos deverão estar devidamente registrados, para então serem incluídos num programa de manejo integrado de doenças pós-colheita de frutos de melão.

TABELA 1 - Avaliação da eficiência de fungicidas no controle de Fusarium pallidoroseum, agente causal de podridão pós-colheita de frutos de melão (Cucumis melo) cv. Orange Flesh armazenados em ambiente refrigerado durante 15 dias e em seguida mantidos em temperatura ambiente por nove dias, aos 20 dias após a inoculação

\begin{tabular}{|c|c|c|c|c|c|}
\hline Tratamento & $\begin{array}{c}\text { Dose } \\
\text { (g i.a./100 l) }\end{array}$ & Incidência & $\begin{array}{l}\text { Severidade } \\
\text { Inoculado }\end{array}$ & $\begin{array}{l}\text { Severidade } \\
\text { Pedúnculo }\end{array}$ & $\begin{array}{l}\text { Tamanho } \\
\text { da Lesão }\end{array}$ \\
\hline thiabendazole & 30 & $0,33 \quad b^{*}$ & $0,33 \mathrm{ab}^{*}$ & $0,00 \quad B^{*}$ & $2,50 \mathrm{a} \mathrm{b}^{*}$ \\
\hline azoxystrobin & 10 & 0,08 & $0,08 \quad \mathrm{~b}$ & $0,16 \quad \mathrm{~b}$ & $0,41 \quad b$ \\
\hline imazalil & 400 & $0,33 \quad \mathrm{~b}$ & $0,25 \quad \mathrm{~b}$ & $0,00 \quad \mathrm{~b}$ & $3,00 \mathrm{ab}$ \\
\hline testemunha & --- & $1,25 \mathrm{a}$ & $0,91 \mathrm{a}$ & $1,08 \mathrm{a}$ & $8,91 \mathrm{a}$ \\
\hline
\end{tabular}

*Médias seguidas por letras iguais nas colunas não diferem estatisticamente entre si pelo teste de Tukey ao nível de 5\% de probabilidade 

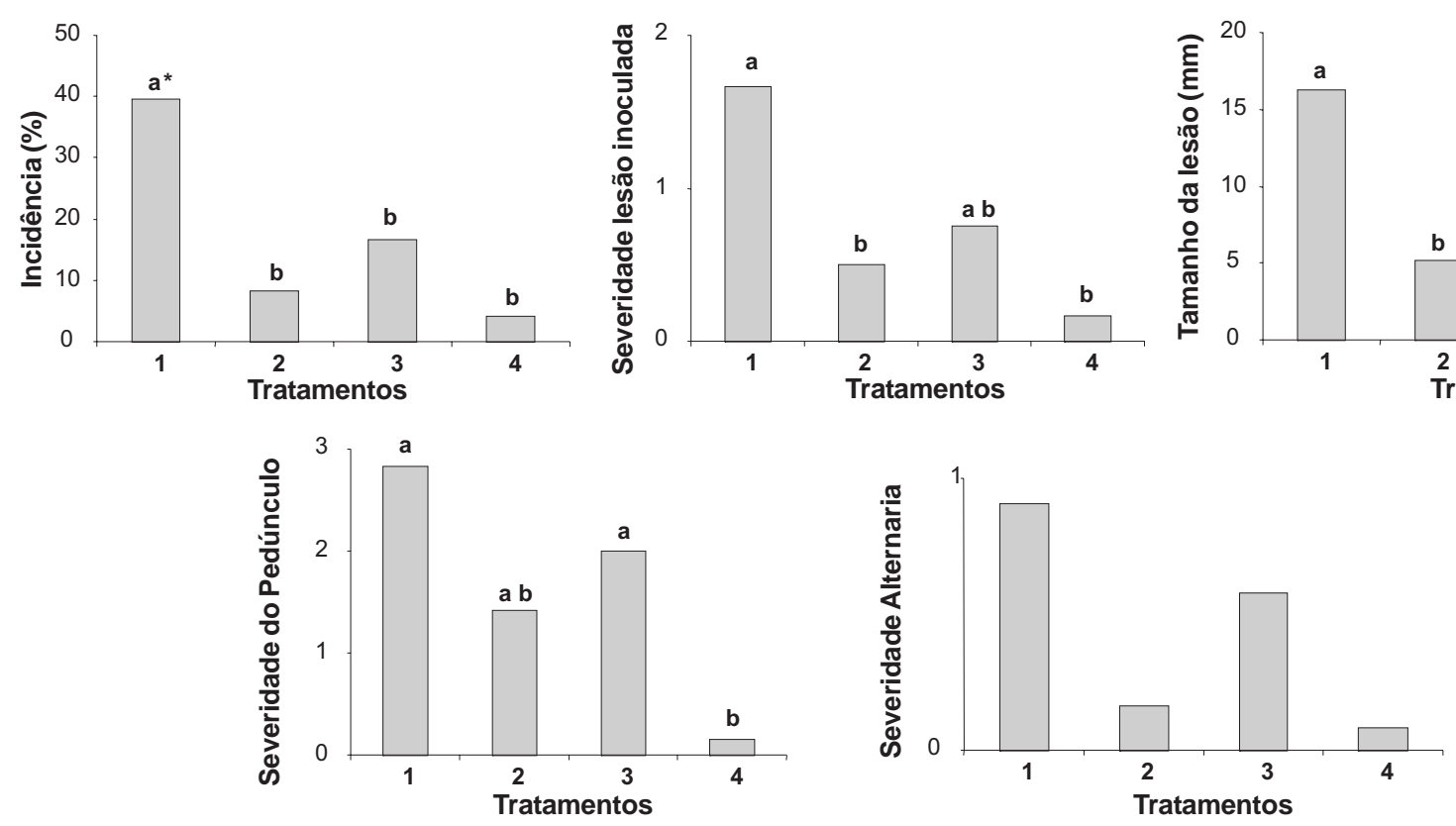

FIG. 2 - Efeito de fungicidas no desenvolvimento de podridões pós-colheita causada por Fusarium pallidoroseum em frutos de meloeiro (Cucumis melo $)$ cv. Orange Flesh, armazenados sob refrigeração, aos 34 dias. 1 = testemunha; 2 = thiabendazole; 3 = azoxystrobin; 4 = imazalil.

\section{REFERÊNCIAS BIBLIOGRÁFICAS}

AHARONI, Y., FALLIK, E., COPEL, A., GIL, A., GRINBERG, S. \& KLEIN, J.D. Sodium bicarbonate reduces postharvest decay development on melons. Postharvest Biology and Technology 10:201-206. 1997.

ANDRiguetTO, J.R. \& KOSOSKI, A.K. Alavanca para exportação. Revista Cultivar - Hortaliças e Frutas 4:19-21. 2003.

BARLETT, D.W., CLOUGH, J.M., GODWIN, J.R., HALL. A.A., HAMER, M. \& PARR-DOBRZANSKI, B. The strobilurin fungicides. Pest Manangement 58:649-662. 2002.

COLARES, J.S. Uso de defensivos naturais no tratamento póscolheita do pedúnculo do melão. (Monografia de Graduação). Ceará. Universidade Federal do Ceará. 2000.

GADELHA, J.C. Controle preventivo e curativo da podridão póscolheita de frutos de melão com produto alternativo. (Mestrado em Fitotecnica). Ceará. Universidade Federal do Ceará. 2002.

HUANG, Y., DEVERALL, B.J., TANG, W.H., WANG, W. \& WU, F.Wp Foliar application of acibenzolar-S-methyl and protection of postharvest rock melons and Hami melons from disease. European Journal of Plant Pathology 106:651-656. 2000.

NAKAUNE, R., ADACHI, K., NAWATA, O., TOMIYAMA, M.,
AKUTSU, K. \& HIBI, T. A novel ATP-binding cassate tranporter involved in multidrug resistance in the phytopathogenic fungus Penicillium digitatum. Applied Environmental Microbiology 64:3983-3988. 1998.

PRUSKY, D., BASAK, M. \& BEN-ARIE, R. Development, persistence, survival and strategies for control of thiabendazoleresistant strains of Penicillium expansum on pome fruits. Phytopathology 75:877-882. 1985.

ROSENBERG, D.A. \& MEYER, F.W. Postharvest fungicides for apples: development of resistance to benomyl, vinclozolin, and iprodione. Plant Disease 65:1010-1013. 1981.

SNOWDON, A.L. A colour atlas of postharvest diseases and disorders of fruits and vegetables: general introduction and fruits. London. Wolfe Scientific. 1990.

SOMMER, N.F. Postharvest handling practices and postharvest diseases of fruit. Plant Disease 66:357-364. 1982.

SPOTTS, R.A. \& CERVANTES, L.A. Populations, pathogenicity, and benomyl resistance of Botrytis spp., Penicillium spp., and Mucor piriformis in packinghouses. Plant Disease 70:106-108. 1986.

SUGAR, D. \& POWERS, K. Interactions among fungi causing postharvest decay of pear. Plant Disease 70:1132-1134. 1986. 